\title{
SEEKING TO IMPROVE AFRICAN AMERICAN GIRLS' ATTITUDES TOWARD SCIENCE
}

\author{
A Participatory Action Research Project
}

\begin{abstract}
A B S T RA C T
In this participatory action research study, we answered the question, How can we improve attitudes toward science education of the African American girls at an elementary school? Girls in grades 3-6 completed the Modified Attitudes toward Science Inventory. A purposeful sample of 30 girls participated in several focus-group interviews throughout the year. The cumulative findings indicate that our initiative (1) had positive impacts on girls who originally demonstrated low self-efficacy in science education or low attraction to science and (2) maintained the positive attitudes of the other girls. The instructional aspects of our initiative that contributed to the improvement in attitudes included the establishment of collaborative activities, a supportive lab teacher, and inquiry-based experiences focused on local problems. Our findings also reveal aspects of our efforts that we need to improve. These areas include a more open, inquiry-based science fair and connections between the lab and classroom teachers.
\end{abstract}

\author{
Gayle A. Buck \\ INDIANA UNIVERSITY \\ Kristin L. Cook \\ BELLARMINE UNIVERSITY \\ Cassie F. Quigley \\ CLEMSON UNIVERSITY \\ Pearl Prince \\ Yvonne Lucas \\ GARY COMMUNITY \\ SCHOOL CORPORATION
}

C I E N CE is an increasingly significant part of our society; not only is it a critical component of a student's educational experience, it is essential for understanding and addressing many of society's most pressing current and future challenges (National Research Council, 2012). Unfortunately, many students continue to be underserved by science education, jeopardizing their ability to attain their career goals and become active citizens, ultimately costing the nation

THE ELEMENTARY SCHOOL JOURNAL VOLUME 114, NUMBER 3

(C) 2014 by The University of Chicago. All rights reserved. 0013-5984/2014/11403-0006 $\$ 10.00$ 
the contributions they might have made. Achievement gaps are well documented for Black, Hispanic/Latino, and American Indian students. Girls' interest in science declines more than that of their male classmates as they move through the science pipeline, and women continue to be underrepresented in a number of science fields (National Research Council, 2012). Equity issues persist in science education, and concerns about them must be at the forefront of our educational efforts.

Although these equity issues persist in science education, the field has made substantial strides in responding to the needs of one population underserved in science-girls. Over the past 40 years, educational research has provided us with a greater understanding of pedagogical practices that meet the needs of girls (Scantlebury \& Baker, 2007). This had led to changes in science education practice and resulted in a greater involvement in science by girls. The average test scores for girls, from elementary to college entrance exams, have risen or remained constant over recent decades (Corbett \& Hill, 2008). For example, in 2011, 35\% of males and $28 \%$ of females scored at proficient or advanced levels on the science component of the National Assessment for Education Progress. Although gender inequalities remain in $\mathrm{K}-12$ science education, notably interest and persistence in physics, chemistry, and engineering, the achievement gap is lessening. This improvement, unfortunately, is not true for all girls. Only $10 \%$ of Black students performed at proficient or advanced levels, whereas $43 \%$ of Caucasian students scored at these levels (Aud et al., 2011). The females in these underserved groups continue to fall short in scientific areas that could propel them to success as adults (Tatum, 2003). The educational inequalities regarding girls from underserved racial groups must be considered a crisis much in same way that it has been for girls in general.

The purpose of our research is to increase our understanding of how to engage elementary-age girls in science-young girls who cross the traditional categorical boundaries of gender and race in a manner that has left their needs and experiences largely neglected. This process cannot occur disconnected from the schools of these girls. If we are to create meaningful and lasting reform, we must possess a deep understanding of the issues the educators of girls are facing (Anderson \& Mitchener, 1994). Thus, together with elementary educators of young African American girls we developed and sought to answer the question, How can we improve attitudes of the African-American girls toward science at an elementary school? Our focus on student attitudes emerged because almost $30 \%$ of the girls at the school our research team collaborated with had negative attitudes toward science at the beginning of our efforts. Britner (2008) demonstrated that attitudes are a crucial link in understanding these voices and how girls are positioning themselves in science and science education.

\section{Theoretical Underpinnings}

We were seeking to create an elementary school environment more conducive to the science education needs of African American girls. To work toward this goal, we had to first insure that we were indeed making their needs the center of our reform efforts. Our understanding regarding equity issues in education has advanced greatly in the last several decades. The research advancing this understanding, however, has approached topics of diversity from vastly different theoretical perspectives on difference that can complicate reform efforts if not explored. This is especially true 
when working with populations that cross the traditional categorical boundaries (e.g., gender, ethnicity) of diversity. In light of this, we first needed to establish the theoretical approach that would guide our initiative.

Over the past 40 years, we have come to understand that gender does make a difference in science teaching and learning. Research revealed that girls tend to be more relational and cooperative and less competitive than boys (Belenky, Clinchy, Goldberger, \& Tarule, 1997; Brotman \& Moore, 2008). Multiple studies have also shown that the masculine image of scientists has created an impediment for elementary girls' involvement in science education (Buck, Leslie-Pelecky, \& Kirby, 2002; Kahle \& Meece, 1994) and has been found to affect their career choice as their desired future images and their image of scientists clash (Packard \& Wong, 1999). In addition, research demonstrated that girls tend to strive for deep conceptual understanding over rote memorization (Zohar, 2006). Although we certainly have more work to do, research has clearly demonstrated that the gender of our students does make a difference in science education, and a substantial number of empirical studies are available to guide reform efforts in regard to improving young girls' attitudes toward science. Much of this research, however, does not consider race or cultural identity (Chavous, Rivas-Drake, Smalls, Griffin, \& Cogburn, 2008; Rollock, 2007; Scantlebury \& Baker, 2007).

Cultural identity also has a significant impact on students' achievement and attitude toward school. (Hardiman \& Jackson, 1997; Helms \& Cook, 1999). Catsambis (1995) showed that African American students' attitudes are often positive despite low achievement. It is suggested that this attitude-achievement paradox may be related to factors external to the classroom (e.g., family, community). Furthering our understanding of such related factors is an increasing amount of writing attending to African American student identities in relation to their attitudes toward science and science education. Kane (2011) showed how three dimensions of science identity (competence, performance, and recognition) shaped how third-grade students constructed their notion of "self." From work such as this, we have come to understand that in order to improve African American students' attitudes toward science, we need to be concerned about the development of strong science identities. Efforts to characterize the pedagogical improvements that would better support the formation of positive science identities are increasing (e.g., Boykin, 1986; Simpson \& Parsons, 2008). Although not as vast as the research on gender, research on cultural identity has clearly demonstrated that this identity does make a difference in science education, and a substantial number of studies are also available to guide reform efforts in regard to improving young African American students' attitudes toward science. Much of this research into students' cultural identities and science education, however, does not consider gender (Collins, 1990).

The combination of gender and cultural identity has a significant impact on students' achievement and attitude toward school. These girls are uniquely affected by school experiences as they are faced with a "two-tiered dominating patriarchy" that consists of race and gender (Fordham, 1993, p. 5). Research has shown us that African American girls often feel the need to be silent or invisible in science and science education. The transition into the culture of science, which is significantly different from their culture, can cause distress and serve to alienate African American females from science (Fordham, 1993). This silencing has not been greatly explored in the literature, as most of the research focuses on reducing the achievement gap of African 
American males or White females (Rollock, 2007). However, the voices of these girls are increasingly being heard. An example of this is the study conducted by Kane (2011). Although this research study was not specifically focused on African American girls, or gender differences, the findings situated the science identity of an African American female next to that of an African American male. There were substantial differences between these two participants that-although not enough evidence alone to specifically claim gender differences in science profiles-does illustrate that there are substantial differences in the science identities of African American students (Kane, 2011). Such studies are increasing our understanding of the types of classroom environments and strategies that would support African American girls' science education.

Britner (2008) demonstrated that attitudes are a crucial link in understanding how girls position themselves in science and science education. Thus, to understand the science education experiences of African American girls, their attitudes about science need to be considered. Weinburgh and Steele (2000) also argued that students' attitudes toward science are important because they are believed to influence the course selection of African American females and ultimately their achievement in science-related fields. Using the Modified Attitudes toward Science Inventory (mATSI) to explore student attitudes in science, Weinburgh (2003) investigated gender and attitudinal differences of fifth graders due to systematic reform. There was a large disparity in attitudes toward science among racial groups. In addition, the mATSI showed that African American girls felt that science is of less value to society and experienced a reduced motivation to engage in science than African American boys. African American females are also less apt to see science as useful and aspire to careers in science (Jolly, Campbell, \& Perlman, 2004). The research on African American girls' attitudes toward science is minimal but increasing, though more research on efforts to systematically improve the attitudes of African American girls toward science is needed.

The present study was focused on young African American girls. As we sought to establish the practical underpinnings of our reform efforts, we prioritized current understanding on improving African American girls' attitudes toward science. We believed, however, that our efforts could also benefit from the more extensive research bases on gender and cultural identity; thus, we utilized research-based strategies found to improve girls' attitudes or African Americans' attitudes toward science as well. However, we were careful not to simply assume an additive approach (Collins, 1990). We understood that we could not solely develop our efforts by adding the pedagogical needs of African American students to the pedagogical needs of girls. In light of this, we took several additional steps in the development of this study. First, we utilized research-based strategies from research exploring gender or cultural identity, and we selected strategies that were found to improve the attitudes of both African Americans and girls. These strategies and the associated empirical support can be found below in the section "Intervention." Second, we developed an action research-based initiative designed to give voice to the African American girls participating in the reform initiative in a manner that would allow them to actively guide our efforts. When we speak of voices, we are referring to more than words. We are referring to an individual's point of view or understanding of reality (Belenky et al., 1997). 


\section{Method}

\section{Context}

Over the course of a year and a half, individuals from Indiana University and an elementary school developed a participatory action research group focused on fostering a science focus in the school. The majority of the approximately 350 girls at this particular school lived in one of two public housing developments within four blocks of the school. The student population was 99\% Black and 1\% multiracial, with the majority of the girls being African American. Additionally, $88 \%$ qualified for free lunch. The school was in its second year of restructuring into a science-focused academy. Science was valued by the faculty prior to our involvement, as illustrated by the fact that the faculty elected to create a science focus, and the subject was an integral part of the curriculum. Science was taught from what would be considered a traditional elementary science education approach (i.e., heavily guided by the textbook and a few areas or displays specifically devoted to science throughout the school). Although a few teachers included some hands-on activities in their plans, those activities were "cookbook" activities focused on reinforcing facts presented in the reading. Prior to our intervention efforts, the girls took a science attitude survey which revealed that approximately $29 \%$ of the girls demonstrated low levels of confidence in science education, high anxiety in doing science, low desire in pursuing education, low value for science, or a combination of these negative attitudes.

\section{Intervention}

Our collaborative intervention efforts began with several teacher professional development initiatives. From the collaborative discussions associated with those teacher development initiatives and subsequent review of contemporary understandings of the pedagogical strategies that improve diverse students' attitudes toward science education, the following initiatives were selected, initiated, and studied in a manner that would lead to further reform. The following research-based initiative became a part of this participatory action research study.

Collaborative problem-based learning throughout the grade levels. Our first major initiative was to collaborate with the classroom teachers to design, implement, and evaluate one fourth-grade problem-based unit. Following this largegroup effort, five doctoral students joined forces with the teachers to work in smaller groups to develop and implement problem-based units across the various grade levels. These units stemmed from teacher interest, recommended standards, and the pooling of resources provided by both teachers and researchers as recommended in research (Moje, Tehani, Carrillo, \& Marx, 2001; Tal, Krajcik, \& Blumenfeld, 2006). Research has shown the positive effects of varying types of instruction centered on student voice and relevancy to the community for both girls (Belenky et al., 1997; Brotman \& Moore, 2008) and African American students (Simpson \& Parsons, 2008). This collaborative learning approach also fosters a sense of communalism and social perspective (Boykin, 1986), which has been shown to be preferred by the parents of African American students (Simpson \& Parsons, 2008). Additionally, because problem-based instruction shifts the focus of science learning away from "correct, indisputable" answers to solutions, 
it creates a dynamic space where power, authority, control, learning, and teaching are shifted between teacher and students (Moje et al., 2001). In an effort to initiate, sustain, and support student engagement, problem-based instruction places students in authentic, contextualized problem-solving environments that bridge classroom experiences with daily life. All these aspects further support the needs of diverse students. For example, one study group developed, initiated, evaluated, and published a unit titled "Deer Tracks in the City" (see Quigley Beeman-Cadwallader, Riggs, Rodriquez, \& Buck, 2009). In this unit, the girls investigated why deer tracks would be in their school yard.

Science lab/lab teacher. Significant differences in class, ethnicity, and gender have made the distribution of resources a major contributing factor to differential success among groups of learners (Calabrese Barton, 2007). Thus, in the initial stages of this project, the university and school worked collaboratively to establish a science lab. This consisted of setting up lab tables, stools, materials, and general science equipment in an empty classroom. The university secured additional funding for lab coats, science activity books, and general science equipment. A fundraiser was held for additional science equipment. The school administration secured a lab teacher, Miss Monroe (an African American teacher), to work with the teachers in grades 4-6. Each classroom in grades 4-6 (and after this study in grades $\mathrm{K}-3$ as well) had a reserved time to go to the science lab twice every week. While there, the girls participated in hands-on, inquiry-based collaborative activities (Cavallo \& Laubach, 2001; Lee \& Burkam, 1996) that supported the current science themes in the various grade levels. The lab teacher was the lead teacher in this lab. The girls wore lab coats and goggles while in the lab. Around the lab, pictures of multicultural and/or female scientists were displayed to counter the stereotypical image of scientists and present a positive image of science as a career choice (Kahle \& Meece, 1994; Packard \& Wong, 1999; Varelas, Kane, \& Wylie, 2011, 2012).

Science fair. During this study, the girls participated in their first science fair. The science fair was originally designed to allow the girls to choose a project based on their interests and allowed them the opportunity to voice their understanding of science (Fordham, 1993). Prior to the science fair, we interviewed the girls about (1) the nature of science, (2) the practices of scientists, and (3) their interests and (4) future scientific investigations. This was done in an attempt to help the girls generate open inquiries. Our findings were shared with the teachers. However, as the science fair approached, the level of inquiry differed among the various classrooms. In some classrooms, the teacher provided the questions and procedures (structured inquiry); in others, the teacher provided the questions and had the girls come up with the procedures (guided); and in others, the girls came up with their own experiment (open). However, within the seemingly open inquiries, the resulting experiments became very much structured as the girls were provided with many books of experiments and most selected one and completed it as written. All girls presented their experiments to teachers, community members, and this research group in a schoolwide science fair at the end of the academic year. The school personnel elected to make the science fair a competitive event in order to allow the girls to take part in a district-wide event in which the winners from the various schools came together to compete. However, a school-wide effort was made to celebrate the achievements of all of the girls participating in the fair. 


\section{Methodological Approach}

We used participatory action research to guide our work. Participatory action research involves taking the construction and reconstruction of our own social reality into our own hands (Kemmis \& McTaggart, 2000). It is appropriate "when people want to think 'realistically' about where they are now; and . . . how, in practice, things might change (Kemmis \& McTaggart, 2000, p. 573). This participatory action research study used qualitative and descriptive quantitative data. In order to gain a deeper understanding of how the intervention outcomes differed depending on the girls' original attitudes, we began by creating participant groupings based on presurvey scores. Then, each participant grouping was analyzed in order to discern how this particular group of girls was affected by the initiatives. We elected to use the quantitative data in a descriptive manner to allow for the representation of girls from various starting attitude orientations. Describing the survey scores in this manner allowed us to explore trends within the various groups to better understand the overall pre/post scores. If we had combined all the survey results, the experiences and needs of the girls that had beginning attitudes that differed from the majority (the largest group) would be lost. As our focus was on informing future efforts at this school (action plan), we felt that this would prevent us from realizing a plan that would meet the needs of all of the girls.

Our research question was, How can we improve the attitudes toward science of the African-American girls at an elementary school? Consistent with the evolving theoretical and methodological approaches of our work, we questioned the diversity within gender and actively attempted to work against polarizations of stereotypical categorization. Thus, our research was further guided by the subquestions: (1) Did our initiative lead to improvements in the attitudes toward science of the AfricanAmerican girls who originally demonstrated negative attitudes? (2) Was there a cost regarding the attitudes toward science of girls with preexisting positive attitudes? (3) What instructional aspects of our initiative contributed to any changes?

\section{Participants}

Our participatory action research team included one of the teachers taking part in the professional development guiding the initiative, the principal, one science teacher educator/researcher, and two science education doctoral students. The university researchers had spent a large amount of time at the school site and were involved with many of the reform efforts. The principal and teacher from the school were actively involved in the research. This five-member team included two AfricanAmerican and three Caucasian females.

All students in the classrooms of the teachers that participated in the professional development activities were given parent consent and student assent forms. Of the 89 responding student participants, 33 were from the fourth grade, 16 were from the fifth grade, and 40 were from the sixth grade. All 89 students were given the presurvey, and their data were used to develop the original orientations and initiative. After the attitude orientation groups were established, we developed a research agenda focused on improving attitudes toward science education. The first of these projects was this action research study. All 89 of the girls that took the presurvey took part in the initiatives associated with this study. As part of this action research study, 66 of 
these student participants, those that we verified completed the majority of first-year activities in the initiative as well as the postsurvey, were used to develop the pre/ postfindings. We used a purposeful sample of these survey participants for the group interviews. Together with the classroom teacher and school administrator, we selected 30 girls. The sample was selected to represent the girls from the various grade levels (10 from each grade level) and the various achievement levels (low, average, high). Consistent attendance was also a selection criterion. The academic achievement on the statewide standardized tests of the participant group (22\% high, $52 \%$ medium, and 26\% low in English and 22\% high, $42 \%$ medium, and 36\% low in math) was representative of the entire school (24\% high, 50\% medium, and $26 \%$ low in English and $23 \%$ high, $45 \%$ medium, $32 \%$ low in math). All girls in the sample came from similar socioeconomic situations (all qualified for free lunch) and were members of the racial makeup of the study (100\% African American).

\section{Data Collection and Analysis}

Phase 1: Establish groupings. When we first came to the school, we had the girls complete the Modified Attitudes toward Science Inventory (mATSI) (Weinburgh \& Steele, 2000) prior to any reform efforts. The developers of the mATSI shortened the original 48-item instrument, developed by Gogolin and Swartz (1992), which was used to gauge science attitudes. The modified 25 -item questionnaire was adapted to measure fifth-grade African American girls' and boys' attitudes toward science. The adjusted/shorter version maintained the validity of the original questionnaire (see Weinburgh \& Steele, 2000). The modified questionnaire contains five subgroups of items: "perception of the teacher," "anxiety toward science," "value of science to society," "self-confidence in science," and "desire to do science." A six-point Likert scale, ranging from "strongly agree" (1) to "strongly disagree" (6), is utilized. For purposes of statistical analysis, we reversed the scales so that positive answers received higher scores and negative responses received lower scores. We also recoded the "anxiety" subgroup as "nonanxiety" because we considered low anxiety a positive response. As well, we chose to omit the survey questions on "perception of the teacher" from the analysis, because the girls had several teachers with whom they worked throughout each day and the survey only gauged their perceptions of a single teacher.

A summary score was created for each of the four subgroups by averaging the items for each category of questions. Based on a preliminary analysis of our survey data, we theorized that the four scales could be condensed into two. We conducted a two-factor exploratory factor analysis with varimax rotation on summer scale scores for the four subgroups of Desire, Value, Nonanxiety, and Confidence. We extracted a two-factor solution that accounted for $75.6 \%$ of the total variance. Scale reliability measures showed items in two factors, Desire/Value and Confidence/Nonanxiety, were highly reliable, with Cronbach's alpha values of .763 and .746, respectively. As a result, we were able to organize two categorizations from the original four subscales identified by Weinburgh and Steele.

To define each category of students, we computed a mean score for each student of attraction to science (made from desire and value items) and self-efficacy in science education (made from confidence and nonanxiety items). We considered these two constructs to be factors that described the data more simply and also allowed for 
a more reasonable discussion of classroom strategies to address the orientations toward science of students explicated by the initial survey. To understand these varying orientations toward science and science education of students in our population $(N=89)$, the students were divided into groups based on their two new summary scores. The Attraction to Science scale and the Self-Efficacy in Science Education scales were each split at the midpoint (3.5 on the 6-point Likert scale) to differentiate students who were distinguished as high or low on each scale. Four groups were then created with those that were high on each of the two, low on each of the two, or high on one scale and low on the other scale. These were as follows: Group 1, High Attraction/Low Self-Efficacy: These girls valued science and expressed a desire to do science, but they doubted their abilities to achieve in the science classroom. Group 2, Low Attraction/High Self-Efficacy: These girls did not value science and expressed little desire to do science, but they were confident in their abilities to achieve in the science classroom. Group 3, Low Attraction/Low SelfEfficacy: These girls did not value science, had little desire to do science, and were not confident in their abilities in the science classroom. Group 4, High Attraction/High Self-Efficacy: These girls expressed a high desire and value for science, and were confident in their abilities to achieve in the science classroom.

\section{Phase 2: Generate findings based on starting orientations.}

Survey data. The survey administered prior to grouping the girls was administered again after a year. The pre- and postintervention data were then used as descriptive statistics in our qualitative analysis to further enhance our understanding of any change patterns. As such, the scores were not used to make generalizable trends across the entire research population; instead, they were used to reveal trends within various subgroups, trends that were then used as qualitative data. In order to determine if there was a change between the girls' prescores and their postscores, we performed a chi-square analysis using the survey data. We sought to illuminate the specific factors within each profile that contributed to the changes in emotional engagement toward science. In order to do this, we explored whether there was a systematic difference between students' pre- to postscores as a function of the students' original profile. Our null hypothesis was that no relationship between pre- and postscores exists. Our chi-square analysis showed that there was indeed no evidence to suggest that knowing the preprofile group would allow us to determine which group the girls would end up in at the end of the treatment. In effect, values of the preprofile were independent of the postprofiles (Pearson chi-square $=.142$; see Table 1). However, the actual data demonstrated that the girls in each profile had a positive increase in attraction to science and self-efficacy in science education at the end of the year. The following qualitative analysis of the trends that emerged looked into the specifics of each profile to describe where the changes occurred. This was used in combination with the interview data (described below) to illuminate the specific factors within each profile that the girls believed contributed to the changes in their attitudes toward science.

Focus-group interviews. Each focus group consisted of three or four girls, all from the same attitude orientation as established above. Focus groups interviews were selected because they are (1) socially oriented and a more comfortable arena for talking about perceptions, as well as being conducive to reflection on the ideas of others (Reinharz, 1992); (2) a safe environment where participants can share ideas, beliefs, and attitudes in the company of people from the same socioeconomic, ethnic, 
Table 1. Girls' Attitudes toward Science Before and After Intervention

\begin{tabular}{|c|c|c|c|c|c|c|}
\hline \multirow{2}{*}{$\begin{array}{l}\text { Starting Attitude and } \\
\text { Orientation Grouping }\end{array}$} & \multirow[b]{2}{*}{$N$} & \multicolumn{2}{|c|}{ Pretest } & \multicolumn{2}{|c|}{ Posttest } & \multirow{2}{*}{$\begin{array}{c}\text { Differences } \\
\text { between Tests } \\
\quad(t \text { Value })\end{array}$} \\
\hline & & Mean & $S D$ & Mean & $S D$ & \\
\hline \multicolumn{7}{|l|}{ High attraction/low self-efficacy: } \\
\hline Attraction to science & 11 & 4.7 & .65 & 4.5 & .89 & -.603 \\
\hline Self-efficacy in science education & 11 & 3.2 & .46 & 4.0 & .89 & $2.37^{*}$ \\
\hline \multicolumn{7}{|l|}{ Low attraction/high self-efficacy: } \\
\hline Attraction to science & 5 & 3.1 & .13 & 4.8 & .71 & $4.64^{\star}$ \\
\hline Self-efficacy in science education & 5 & 3.8 & .35 & 4.7 & 1.1 & 1.89 \\
\hline \multicolumn{7}{|l|}{ Low attraction/low self-efficacy: } \\
\hline Attraction to science & 3 & 2.7 & .61 & 4.6 & .91 & 2.90 \\
\hline Self-efficacy in science education & 3 & 2.3 & .56 & 3.8 & .60 & 2.21 \\
\hline \multicolumn{7}{|l|}{ High attraction/high self-efficacy: } \\
\hline Attraction to science & 47 & 4.7 & .60 & 4.6 & .75 & -.715 \\
\hline Self-efficacy in science education & 47 & 4.7 & .68 & 4.6 & .82 & -.765 \\
\hline
\end{tabular}

and gender backgrounds (Madriz, 200o); and (3) inclusive in that they limit the powerful voice of the researcher (Wilkinson, 1999). The foci of the interview included questions about attitudes toward science, attitudes toward science education, the relative importance of science (as an area of study and school subject), and favorite science lessons. Sample questions included (1) "Do you feel that you do well in science at school? What would help you do better?" (2) "Is it important for you to do well in science at school? What is more important than studying science?" and (3) "Tell me about your favorite science topic. Do you explore this topic on your own?" We took steps to insure that the girls were familiar with the interviewer by having her introduce herself to the girls and make several initial visits to the school prior to the interviews. The five interviews were conducted in October, November, February, April, and June.

All members of the research team reviewed the transcriptions. We coded the data by profiles to represent the girls' own words as closely as possible and explored the trends. We analyzed the database using traditional qualitative procedures for coding and developing themes (Creswell, 2008; Creswell, Plano Clark, Gutmann, \& Hanson, 2003). We coded the data in a manner that would allow us to identify the various types and levels of attitudes within an instructional context. First, it was noted each time the girls referenced an example of desire, value, confidence, and nonanxiety. Next, the examples were further coded by the instructional reference. We refined the codes throughout the coding process as new ideas emerged. His open-coding process included segmenting the meaningful units and assigning codes to label each segment (e.g., self-efficacy/science lab, self-efficacy/problem-based unit, selfefficacy/science fair). The final analysis explored the various instructional experiences in regard to the two broad themes of emotional engagement (attraction to science, self-efficacy in science education). These themes served as a focal point for exploring the experiences of each orientation group, highlighting how their emotional engagement changed (pre-post) and the aspects of our initiative that fostered or hindered girls' emotional engagement in science education.

Phase 3: Generate new plan of action from cumulative findings. The final phase of the analysis was to develop a holistic understanding from the individual groups in 
a manner that would inform further action. The review process followed the same general structure as noted above for the individual groups. We reviewed the findings from the various groups for the types and levels of attitudes within an instructional context. However, in this cumulative review, the categories of Group 1, Group 2, Group 3, and Group 4 were added. In this manner, we were able to make a statement about the similarities and differences among the girls. The themes that emerged in the analysis of the groups then served as a focal point for exploring the experiences across the overall student population in the upper elementary grades at this one school.

\section{Results}

In this section, we address our first two research questions separately. These are (1) Did our initiative lead to improvements in the attitudes toward science of the African-American girls originally demonstrating negative attitudes? and (2) Was there a subsequent cost in regard to attitudes toward science education of girls with preexisting positive attitudes? Our third research question (What instructional aspects of our initiative contributed to any changes?) is addressed throughout. We focus only on the changes (positive or negative). We describe the patterns identified in the individual groups, using sample quotes from individuals within the group as supporting evidence. All names are pseudonyms to protect confidentiality.

\section{Instructional Initiatives That Improved the Attitudes of Girls Originally Demonstrating Negative Attitudes toward Science}

Change for girls starting with high attraction to science/low self-efficacy in science education. This group is made up of the girls who found science appealing but demonstrated a low sense of self-efficacy in science education at the beginning of the reform process. For these girls, the goal of our intervention efforts was to increase their self-efficacy while maintaining their attraction to science. Our findings demonstrated an increase in self-efficacy level, with the mean increasing from 3.1773 to $3.9841(N=11)$ (see Table 1$)$. Thus, the girls who began the school year having low self-efficacy became more confident throughout the year. In addition, our findings showed that these girls continued to find science attractive.

Because the girls were interviewed five times throughout the year, we were able to document reasons underlying this positive change. This group of girls began the year demonstrating their attraction to science with frequent references to doing science activities outside of school. For example, Kylie remarked, "I be adding like we don't really have stuff like the science lab, but my mama be getting the stuff that we need when we at science lab, me and my sister we be like making — adding baking soda and see what'll happen if we add like sugar to it and then add water." Kylie described her interest in trying experiments at home, which indicated she had the desire to do science. In these early interviews, however, her attitude quickly changed when we started to talk about science in the lab or classroom. She expressed that she didn't know if she was doing things correctly and did not feel confident in her ability to get good grades. She noted, "I just don't know how to write it. And it is very hard trying to say it 'cause it makes no sense when you try and say it. Because I'm not pretty good at science, but I like it." 
The other girls in this group expressed similar attitudes, noting that they enjoyed science but were not confident when it came to answering questions or explaining what was occurring in an experiment. They also made several comments about hands-on science activities in school and how they "messed them up." For example, Dionne noted, “The clay boat, it kept sinking-'cause we didn't know how to make the boat, it kept sinking." Deja was another student in this group who said that although she loved "doing experiments," she became frustrated at not knowing the answers in lab: “That's when people are talking. She's [the teacher] trying to get their attention. But sometimes it make you feel bad inside. Like I don't know this answer so what's she expect me to do?"

We noted that many of these girls began asking more questions about science while at school. Through our professional development efforts, teachers had been trained on how to encourage questioning in the classroom, and many of these girls' growing confidence in science education was demonstrated by their increasing willingness to ask questions during the activities. They also elected to redo experiments when given the opportunity. For example, when Miss Monroe gave Dionne's group the opportunity to redesign their clay boat, pride over the eventual success on the project was displayed when Dionne claimed: "The clay boat was my favorite. ... I took some home and I took some pictures and stuck it on my wall.” Her experiences of success in the science lab helped to enhance her confidence in her abilities to participate in experimentation and inquiry. Many in this group also began demonstrating an increase in self-efficacy during the lab group activities when they were assigned roles that allowed them to make valuable contributions. For example, Kylie noted, "My favorite lesson has been when I'm the monitor in my group, so every time we do an experiment, I get up and get the materials and I get to wear the goggles." As she began to succeed in her designated role as the monitor in her collaborative learning group, she began to gain confidence in her ability to do well in science.

During the final focus group interview, when asked again about their experiences with science, these girls were more confident. For example, when asked how she would grade herself in science, one of the girls noted, "Probably an $\mathrm{A}++$, 'cause science is my favorite-it doesn't seem like it, but it's my favorite subject cause I like learning things about outer space." She was referencing a collaborative problembased unit on space. Her experiences with both the classroom problem-based learning and in the science lab seemed to boost her confidence in being successful in science. Similarly, Kylie and Dionne said they would also get an A, Dionne explaining that this was because "in experiments I'm good and in science I'm good." When asked how she came to resolve the difficulties in science that she described in earlier discussions, she simply stated that she asks the teacher for clarification. This is one of several references to the lab teacher; others noted that they did well because "she [Ms. Monroe] wants us to do good. It disappoints her really bad when we don't do well." For the majority of girls in this group, their experiences of success in the science lab, contributions to group experiences, and relationship with the science teacher helped to enhance their confidence in their abilities to participate in experimentation and inquiry.

However, not all the girls in this group demonstrated an increase in self-efficacy. For example, Deja maintained her low sense of self-efficacy in science even at the end of the year. She continued to voice her frustration with science when she remarked that she still had difficulty with the experiments. Despite the introduction to the 
science lab and inquiry-based lessons, she did not have an increase in self-efficacy with regard to science education. We did note that Deja discussed her preference for quiet reading about science as her preferred learning style. She said, "I'm a good reader, I can read, and I catch onto things quickly." When asked about how she would like science to be taught she stated, "Like, if sometimes I could go to the library almost every day. And if I just get a science book and read about science like cells and animals." Over the course of the year, Deja continually talked about frustration with her group dynamics in the lab and being unhappy with her assigned role as the secretary for her group. It is possible that the group working environment actually inhibited growth in her confidence level.

Change for girls starting with low attraction to science and high self-efficacy in science education. This group of girls perceived themselves as capable of doing science well, but did not express interest in or excitement about doing it. For them, the goal of our intervention efforts was to increase their attraction to science while maintaining their high levels of self-efficacy. There was a significant increase in attraction (3.1395 to 4.8086), and the mean for self-efficacy also further increased from 3.8250 to $4.6850(N=5)$ (see Table 1 ).

In the beginning, most of the girls saw very little value in science in regard to their future careers, perceiving that if one "wants to be an actress" or a singer, then science was not important. Many noted that they did well in science because it was important to do well in school to pass the grade, but they saw no difference in being successful in science than in other subjects. For example, Janae expressed that she simply did not enjoy science as much as other subjects. But, as with the others, despite this level of attraction to science, she was confident in science education and stated that she typically received A's in science due to being a good listener and getting correct answers: "I listen to get the answer."

As we interviewed this group of girls throughout the year, they increased their attraction to science. Despite their future interests not always aligning with science in obvious ways, they came to appreciate being involved in science. Throughout the year, the girls in this group responded with an increased attraction to the science lab, teacher, and the inquiry-based lessons. Laboratory experiences such as an investigation of owl pellets gave her an understanding of why science is important: "I think it's important because you need to know, like, what's going on in the world mostly like what's going on in the world. Like the owl bones, you know what they eat and what types of animals are." Similarly, the girls in this group noted positive interactions with the science teachers. "Because the science teacher comes up and says 'Oh, you're doing well, you're doing well.' They give me compliments.” Cara noted that the teacher helped them when they needed it ("[she] helps us when we need help") but encouraged them to figure it out on their own ("she just give us clues" or "sometimes she doesn't [give the answer] because we don't need help).” In fact, the relationship made so much of an impact on Cara that at the end of the year, she declared she wanted to be a scientist when she grew up. Extending this relationship with her science teacher to others in her life, Cara showcased her desire to participate in science by assuming the role if the teacher at home with her brothers: "Me and my brothers be getting some stuff, we be asking mom can we get this and she be saying yes, so we be making stuff. Like today I was going to teach them how we did the stuff in science class." Not only did the relationship with Miss Monroe increase Cara's desire to participate more fully in science, but it transformed her view of science as 
important to her career goals because of the connection it inspired with people through learning science.

By the end of the year, many of the girls in the group made statements such as, "I think that it's worth it to do well in science because I love science-I love science and I want to know more about science. I want to get in it." Even Janae, who noted at the beginning of the year that she simply did not like science as much as she liked other subjects, now claimed that science was her favorite. She noted, "science is my favorite subject because you could learn a lot . . . about science and you could learn a lot about how to make something." Her discussion in the focus group revealed that she really appreciated the aspect of science as not being about one final answer, but more about the process of doing science. She participated eagerly in the inquiry-based labs and took leadership roles in the experiments conducted in the classroom. She commented that she had developed an interest in doing science at home and had tried to figure out why salt melted the ice on the roads by creating her own experiment. She enjoyed posing questions on her own and determining how they could best be answered. She talked at length with her classroom teacher, who provided her with suggestions on how to do her at-home experiments to help her figure it out: "'cause [classroom teacher] told us ... put 2 little cups about like this, we put one cup with water and the other with sugar. Stir . . . the salt up ... put it in the freezer, we had to see which one froze the most. . . . But, the water froze the fastest . . . sometimes I be checkin' on the salt and I be playing with the salt for some reason I don't know. . . . I was looking at it and poking at it and it still wasn't getting cold 'cause I saw the water kind of getting froze.” Janae said that the classroom teacher even asked her to report her findings back to the class. The change we noted in attraction to science among the girls in this profile was very positive, and the reasons that emerged from student interviews suggest that the inquiry-based experiences with their teachers seemed to foster this increase.

The teachers' influence, particularly the lab teacher's, on the girls' experience was notable, as several of them referenced her directly when discussing their connection to science. Most of the girls cared for and enjoyed their interactions with Miss Monroe; however, Dionne described her frustration with her: "I do well but when our science teacher do all that yellin', I just get mad and throw my work together. I do well but sometimes-I love doing the projects- but when she gives us like work to do and she start yellin' 'cause you get an answer wrong. When she gives my paper back, I just put anything on there." Although Dionne did not perceive her experience with the science teacher as positive, her comments further underscored how important the relationship was with regard to desire to do science.

Change for girls starting with low attraction to science and low self-efficacy in science education. In order to reach our goal where all girls had high levels of both attraction to science and self-efficacy in science education, we needed to foster an increase in both these subgroups for this group of girls. We found a large increase in mean in attraction from 2.7286 to 4.5905 and in self-efficacy 2.3250 to $3.7667(\mathrm{~N}=3)$ (see Table 1). Positively, we did not have a large number of girls in this group, since not many students started the year low in both of these constructs. Also positive was that all of the girls in this group increased in attraction to science or self-efficacy in science education, or both.

In the student interviews, we were able to investigate the gains made by the girls in this group. Ariel was one of the students who increased in her attraction 
but did not increase in her self-efficacy in science education. In the early interviews, she claimed she wanted to be a veterinarian because she loved animals and wanted to help them: "About what they do, they see ... and find about what's in them ... and see what they are learning, too." Every time she was interviewed throughout the year, the topic of animals came up as Ariel talked about her dog, Blackie. Over the course of the year, Ariel increasingly saw how science was related to the study of animals. She had the opportunity to do activities like dissecting owl pellets, talking about mammals, and looking at the pictures in her science books that were related to animals. She continued to talk about her dog Blackie during our interview time and seemed to understand that science was the appropriate place to learn about things related to her passion for animals. Time in the science lab conducting experiments and learning about animals fostered in her the desire and value in doing science, but her confidence continued to be relatively low.

The girls in this group also talked about the strategies they used to improve in science. For example, Yvonne, who began the year with the lowest survey scores in terms of her perceptions of science, developed a strong relationship with Miss Monroe and often referenced her desire to please her. Throughout our interviews, she talked about Miss Monroe being kind and supportive. At the end of the year, Yvonne not only made improvements in self-efficacy and attraction, but she actually wanted to be a science teacher: "Science will be important to me by learning how to like learning how to do experiments when I'm science teacher, I'll learn how to do experiments and show the class how to do science projects. I'm gonna try to be a science teacher-like a caring science teacher when I grow up."

While Ariel began to feel connected to science as she learned that it related to her interest in animals, her attraction to science increased. She still, however, had progress to make in terms of her self-efficacy at the end of the year. In the exchange below, Ariel indicates her vague sense of how to improve her grades in science class. When asked about her perceived grades in science, she responded,

Ariel: Sometimes D's, and sometimes I get A's.

Interviewer: So what happens when you get the D's? Why are you getting those grades?

Ariel: Because sometimes I don't understand it, I ask my classmates do they understand it and they say no, so we do the best way we can.

Interviewer: So how do you think you could get your grades, 'cause sometimes you get A's? How do you think you could get those more?

Ariel: If I ask the teacher more questions and listen in class and study more about science and ask my teacher if I can take my science book home.

Though few students began the year with a low attraction to science and selfefficacy in science education $(N=3)$, the girls that did display this disposition showed positive gains in these areas. Similar to the other groups, the lab experiments and topics (especially those that connected with the girls' personal interests), as well as the relationship with the "caring" science teacher, were instrumental in connecting students more deeply to science. 


\section{Was There a Cost to Reform Initiatives in Regard to Girls with Preexisting Positive Attitudes?}

Our goal was to increase the emotional engagement of the $29 \%$ of girls demonstrating negative attitudes in the beginning without negatively impacting the $71 \%$ of girls that entered into the reform efforts with positive attitudes. Unlike the earlier groups, we were not actively seeking significant changes with these girls; instead, we sought to maintain or even improve their levels of attraction to science and selfefficacy in science education while we adjusted the curriculum in an effort to improve the attitudes of their classmates. For the girls in this group, there was little change in means (4.6198 to 4.6094 for appeal and 4.6592 to 4.5553 self-efficacy; $N=$ 47) (see Table 1).

In this group, several of the girls expressed their enjoyment of the experiments they worked on in science lab. Referencing the problem-based learning unit on phases of the moon they worked on in their homeroom classes, Tyonne stated, "We get to learn stuff we didn't know before. And you do a lot of experiments to show all of it and we can find the phases of the moon." The students seemed to appreciate the ability to do experiments to showcase their learning rather than the pencil-and-paper assessments they often were asked to do in other classes. In terms of self-efficacy, some of these girls prided themselves in sharing their knowledge with others in their family. For example, Kaila stated, "Sometimes I bring my science book and learn and do experiments out of it. I do it and then my mom be surprised because I did it all by myself." The chance to show others what they had learned in science class and receive praise from people for doing so was something a number of the girls talked about as important to them. Others discussed the roles of their teachers as important in the confirmation of their abilities: " 'Cause every time I had a question, they just read it to me. Then I asked them again and they come over and tell me what I'm looking for and I see what I'm looking for, then that give me better confidence" (Krystine).

Davina expressed a high level of self-efficacy and attraction to science in her interviews early in the year. In her final interviews and postsurvey, she continued to see science as something within her capabilities and as something desirable with which to engage. Davina wanted to be a nurse because she liked "to help people," and she claimed that the experiments and the discovery possibilities in science were motivating factors: "I think there are still discoveries," and "When I become a nurse, I could figure out medicines to cure people." Though she experienced frustration with classroom activities, she desired to become more proficient at science because she saw it as something she needed to understand in order to become a nurse and help people. She consequently worked hard at science; after the presentation of her science fair project, Davina learned that she won first place. This success confirmed her self-efficacy in science.

Other students in this group came to appreciate the essence of science as discovery-something to which anyone could potentially contribute. Brittany described the importance of scientific discoveries in her daily life and alluded to the fact that opportunities exist to contribute to science: "Miss Harris, she like want us to do good. It disappoints her really bad when we don't do well. Because she want us to learn how she learned and know what she know and sometimes we maybe even can teach her stuff about science that she don't know, because science is-it's like science, everything in science, something get invented like every day or every week.” 
Brittany referenced her science teacher when discussing the importance of scientific discoveries, indicating that she felt supported by Miss Monroe to contribute to science learning and potentially have an opportunity to teach the teacher.

Though rare, there were a couple of girls in this group who actually decreased in one or both constructs. For example, Tyonne began the year high in both attraction and self-efficacy categories, but ended the year low in both. Interviewed several times throughout the year, Tyonne seemed to disconnect from science over time. She expressed early on that she wanted to be a lawyer; she did not see science as relevant to her pursuits: "I'm good at it, but it's not my best subject, I don't think. I don't like science as much. 'Cause when you do science, it's kind of like math where you have to mix all the chemicals together, and it's messy and it's really irritating. Plus, I want to be a lawyer." Here, Tyonne uses her careers aspirations (which she see as having little relevance to science) to explain why she doesn't like to do science. As well, she explains she is not partial to the hands-on aspects of performing chemical lab experiments. As the year went on with more experiments and inquiry-based science, Tyonne talked more and more about becoming a lawyer:

Interviewer: And do you think you'll ever use science once you're a lawyer? Tyonne: I don't really think so. I'm not really a big fan of science. My mom makes me study a lot. I think you need to get high grades in science because like if you decide to be an astronaut or something, you'll going to need to be passing science now so you will know your stuff right now so you can get a job. My mom is into science and stuff and she wanted me to study science, but that wasn't my dream, so I didn't.

Tyonne expressed that science, though she felt she was good at it, was not her interest. She talked about the pressure she felt from her mom to be "into science," and seemed to be distancing herself from science as the year progressed. Unfortunately, this disconnect gave way to a struggle to do well in her science class as material became increasingly difficult for her: "Like when we have to put it together, some of the stuff that they're telling us to do doesn't even make sense. The work be hard and you can't, you only have a certain amount of time to finish this amount of work and it be hard." The pressure of her perception that her mom wanted her to like science along with the in-class pressure of doing timed experiments served to separate Tyonne from her self-efficacy and attraction to science. While Tyonne was unique in that her connection to science in terms of both attraction and self-efficacy suffered over the year, it is interesting to note that not all students had a positive experience with science, despite the hard work of their teachers and introduction to the science lab. Most of the girls (85\%) in this group, however, did increase or maintain their optimistic attitudes toward science.

\section{Conclusions and New Plan of Action}

As an action research team, we spent one and a half years actively working to improve the attitudes of African American girls at one elementary school. Together, we fostered an increase in attraction to science and self-efficacy in science education for many girls at the school. Also, by listening to the voices of the girls taking part in the initiative, we leave the study with understandings that will guide the continuing 
efforts to assure that attitudes, and subsequently skills and achievement, will continue to improve. We now end the action research cycle by turning the conclusions back to our efforts within this school and what they revealed, with a particular focus on how we can improve our practice.

Looking across the findings, we see the establishment of a science lab and providing a lab teacher had, by far, the most noted impact as far as the girls were concerned. The girls who started with low self-efficacy in science education frequently noted that the inquiry-based, hands-on experiments in the science lab contributed to their increase in self-confidence in science. They referenced the opportunities to perform experiments again if they did not go well the first time around and that they were allowed the freedom to inquire and explore their own questions within the laboratory setting. The exposure to and confidence they gained from these hands-on experiences transferred to their home environments, where they provided us with examples of how they showcased what they had learned with their family or further investigated their additional questions. References to the lab also appeared in the cases of the girls that started with low attraction to science. For these girls, the lab was described as exciting and enjoyable as they were provided opportunities to explore interesting topics. Thus, the establishment of the science lab had a positive effect on girls from each group; however, it was different aspects of that lab that made a difference. The excitement of the lab and inquiry projects increased the attraction for the girls, but it was only through the establishment of a supportive and nonjudgmental environment within that lab that a greater sense of self-efficacy was inspired in those girls that needed it. That supportive environment was fostered by the lab teacher.

From the frequent references to the lab teacher in response to interview questions during most of the focus-group sessions, we can clearly see that the relationship the girls had with the lab teacher strongly supported their increases in attraction to science and self-efficacy in science education. For the girls starting with a low sense of self-efficacy, Miss Monroe helped them feel the success of their learning by guiding them through their inquiries and fostering an atmosphere in which the girls could ask questions. The compliments by Miss Monroe on work well done seemed to increase their self-efficacy. For the girls starting with low attraction to science, Miss Monroe was described as a science role model. She worked in science and talked with the girls about their futures and how science plays a role in their successes. Miss Monroe would also encourage the girls to explore science on their own. This encouraged many girls to conduct their own investigations and experiments outside of school. Thus, they began to have a voice in science and showcase their learning to their community (Fordham, 1993). This ability to have a positive relationship with both the teacher and the content describes the connection to relational learning that is often needed in classrooms (Biesta, 2004) and has been found to support the learning needs of African American students (Boykin, 1986). Turning our attention back to our intervention efforts, we can clearly see that this had a positive impact on the girls' attitudes. Our findings support the use of science resource teachers in elementary schools, and our action plan will continue to include this teacher.

The strong findings in regard to the science resource teacher also raise some concerns that further inform our plan of action. Whereas we were surprised by the number of positive references regarding the lab teacher, we were also surprised by the general lack of references to the classroom teachers despite the fact that these teachers 
were present during the time spent in the lab, and they did teach science in their classrooms as well. This is particularly concerning given the fact that science labs and lab teachers are frequently cut in difficult financial times. A couple of references to classroom teachers were noted. An example of such references is the classroom teacher that encouraged the girls to pursue their inquiry about icy roads by conducting an experiment with ice and salt. This fostered these girls' attraction to science. The positive gains that resulted from the relationship with the science lab teacher and those from the few experiences involving classroom teachers suggest that there is a potential for science relationships with the classroom teachers, but our current plan did not foster such science relationships. Our future plans include a more cohesive connection between the lab activities and the classroom activities. We plan to support the classroom teachers as science teachers as well and encourage them to have a much stronger role in supporting the girls through the inquiry-based instruction within both the lab and classrooms. We also believe classroom activities need to include inquiry-based approaches and not simply include the prerequisite reading or follow-up reflection. In addition, our future development efforts for the classroom teachers need to include more of an emphasis on becoming a science role model for their students.

Importantly, not all girls' sense of self-efficacy increased throughout the year. This small group of girls referenced the difficulty of scientific vocabulary and dislike for experiments or group work as the reasons for their lack of confidence in science. This suggests that providing opportunities for different learning styles may help to support more students. Though the collaborative nature of the laboratory work was a benefit to most of the girls with whom we spoke, not all of the girls appreciated the collaborative nature of this work. Some of the girls felt that their peers slowed them down, and consequently they did not enjoy the pressure of group lab work. This was not anticipated by the research group at the beginning of the project and is found to counter much of the empirical work in this area. Practically, this suggests to us that personal benchmarks and assessments, as well as a mixture of collaborative and individual work, may help to better serve the different learning preferences among the girls.

Additionally, by allowing the girls to explore their own questions through inquiry opportunities embedded within problem-based learning units, the environment became more congruent between home and school. This congruence is a crucial part of bridging the disconnect between home and school science that often silences marginalized groups (Calabrese Barton, Tan, \& Rivet, 2008; Kane, 2011; Moje et al., 2001; Simpson \& Parsons, 2008). This was most notable for the girls that started with a low sense of self-efficacy in science. By anchoring instruction in what they already knew, they started with a certain level of understanding. Regarding the girls' attraction to science, the gains that resulted were underscored by how they related science to their emerging interests (Lee \& Luykx, 2007). Several girls referenced the interactions of science in their everyday realities. They began to view succeeding in science as something that they would need to advance in their schooling, as well as something that they need for their future. However, we believe there is much more work to do in this regard. We see only the results of our initial attempts and can see that more opportunities for these connections are needed.

We were disappointed to note that references to the school-wide science fair were rarely found in any form (positive or negative) in the findings. The only group that 
had specific references to this instructional approach came from the girls that started the year with positive attitudes. For these girls, this event seemed to be a chance to showcase their abilities. Although the science fair was not categorized as a negative, there were no references to its presumed benefits. We contend that it was lack of purpose for the fair that may have limited its impact. Although the personnel at the school liked the idea of a science fair, and we did have several initial meetings on fostering inquiry-based projects, when it came down to managing multiple inquiry projects in one classroom, the goal quickly became to get every girl to just complete something. The teacher set out to meet that goal even if it meant giving them an experiment from a book and telling them to follow the procedures. Of note is the fact that all the girls did complete the activity and did not leave with negative feelings about science or the science fair. However, the focus was not on inquiry as originally planned. For most of the girls, it was following directions. In addition, the competition focus didn't seem to mean anything to the girls who didn't believe they had a chance at winning. In the future, we need to clearly establish the purpose of the fair and provide extensive support throughout. In addition, there should be multiple paths to take with the fair overall, with the competitive path being only one.

With this study, we sought to explore the effect of our research-based educational initiative on African-American girls' attitudes toward science as well as the specific factors associated with our initiative that contributed to any identified changes. We assert that the implementation of the lab and lab teacher coupled with the development of relevant inquiry-based science units fostered gains in the students' attitudes toward science. Our work showcases a successful and meaningful approach to elementary science education reform, and we hope to inspire educators to consider the specific needs of the community they work in. If we return to the work by Rollock (2007), who highlighted the need for understanding the silencing of African American girls, our work suggests specific strategies for educators working in these communities. Through this inclusive approach, we emphasize the strengths and the struggles that lie in these communities and bring to the foreground strengths and struggles that lie in this approach to teaching science.

Our research helps to increase an understanding of how to engage girls in science-girls who cross the traditional categorical boundaries of gender and race. Clearly, we understand the challenges of this work and know we have many revised plans of action ahead of us, but, by sharing our efforts, we hope that educators can extrapolate these findings for future work that promotes action-based research in similar settings.

\section{Limitations}

Research on student identities has its limitations for advancing generalizations across populations. Furthermore, attitude survey research is limited in providing deep understanding of student identities. Although we used both surveys and multiple focus-group interviews focused on the girls' perceived experiences in the context of their school science classroom to reduce the limitations of each of the approaches, we acknowledge that our work also includes the limitations of each of those approaches to a lesser degree. We acknowledge that we lost some of the indepth insights into the individual science profiles represented in the population of girls. Likewise, as we sought to gain more insight into the survey data collected by a 
validated instrument, we acknowledge that we lost some of the strength of the ability to generalize to all African American students as had been previously addressed by this instrument (Weinburgh \& Steele, 2000) when we elected to use the data in a descriptive manner. Furthermore, any attempt to produce a replicable intervention is hindered by our use of action research. Our work focused on one school, and we are proud to say that it made a positive impact on this school. We share this work not to provide a finished product, but to further the discussion on the process that is allowing us to foster an improvement in young African American girls' attitudes toward science.

\section{Note}

The authors would like to thank all of the classroom teachers for their many efforts in improving the attitudes toward science of their students.

\section{References}

Anderson, R., \& Mitchener, C. (1994). Research on science teacher education. In D. Gable (Ed.), Handbook of research on science teaching and learning (pp.3-44). New York: Simon \& Schuster Macmillan.

Aud, S., Hussar, W., Kena, G., Bianco, K., Frohlich, L., Kemp, J., \& Tahan, K. (2011). The condition of education 2011 (NCES 2011-033). Washington, DC: U.S. Government Printing Office.

Belenky, M., Clinchy, B., Goldberger, N., \& Tarule, J. (1997). Women's ways of knowing: The development of self, voice, and mind. New York: Basic Books.

Biesta, G. (2004). "Mind the gap!": Communication and the educational relation. In C. Bingham \& A. Sidorkin (Eds.), No education without relation. New York: Peter Lang.

Boykin, W. (1986). The triple quandary and the schooling of Afro-American children. In U. Neisser (Ed.), The school achievement of minority children: New perspectives (pp. 57-92). Hillsdale, NJ: Erlbaum.

Britner, S. L. (2008). Motivation in high school science students: A comparison of gender differences in life, physical, and earth science classes. Lournal of Research in Science Teaching, 45, 955-970.

Brotman, J., \& Moore, F. (2008). Girls and science: A review of four themes in the science education literature. Lournal of Research in Science Teaching, 45, 971-1002.

Buck, G., Leslie-Pelecky, D., \& Kirby, S. (2002). Bringing female scientists into the elementary classroom: Confronting the strength of elementary students' stereotypical images of scientists. Iournal of Elementary Science Education, 14(2), 1-10.

Calabrese Barton, A. (2007). Science learning in urban settings. In S. K. Abell \& N. G. Lederman (Eds.), Handbook of research on science education (pp. 319-343). Mahwah, NJ: Erlbaum.

Calabrese Barton, A., Tan, E., \& Rivet, A. (2008). Creating hybrid spaces for engaging school science among urban middle school girls. American Educational Research Journal, 45, 68-103.

Catsambis, S. (1995). Gender, race, ethnicity, and science education in the middle grades. Iournal of Research in Science Teaching, 32, 243-257.

Cavallo, A., \& Laubach, T. (2001). Students' science perceptions and enrollment decisions in different learning cycle classrooms. Journal of Research in Science Teaching, 38, 1029-1062.

Chavous, T., Rivas-Drake, D., Smalls, C., Griffin, T., \& Cogburn, C. (2008). Gender matters, too: The influences of school racial discrimination and social identity on academic engagement outcomes among African American adolescents. Development Psvchology, 44, 637-654.

Collins, P. (1990). Black feminist thought in the matrix of domination. In P. Collins (Ed.), Black feminist thought: Knowledge, consciousness, and the politics of empowerment (pp. 221-238). Boston: Unwin Hyman.

Corbett, C., \& Hill, C. (2008). Where the girls are: The facts about gender equity in education. Washington, DC: American Association of University Women. 
Creswell, J. W. (2008). Research design: Qualitative, quantitative, and mixed methods approaches. Thousand Oaks, CA: Sage.

Creswell, J. W., Plano Clark, V., Gutmann, M., \& Hanson, W. (2003). Advances in mixed method design. In A. Tashakkori \& C. Teddlie (Eds.), Handbook of mixed methods in the social and behavioral sciences. Thousand Oaks, CA: Sage.

Fordham, S. (1993). "Those Loud Black Girls": (Black) women, silence, and gender "passing" in the academy. Anthropology and Education Ouarterly, 24(1), 3-32.

Gogolin, L., \& Swartz, F. (1992). A quantitative and qualitative inquiry into the attitudes toward science of nonscience college students. Lournal of Research in Science Teaching, 29(5), 487-504.

Hardiman, R., \& Jackson, B. W. (1997). Conceptual foundation for social justice courses. In M. Adams, L. A. Bell, \& P. Griffin (Eds.), Teaching for diversity and social justice: A sourcebook. New York: Routledge.

Helms, J., \& Cook, D. (1999). Using race and culture in counseling and psychotherapy. Needham Heights, MA: Allyn \& Bacon.

Jolly, E. J., Campbell, P. B., \& Perlman, L. (2004). Engagement, capacity and continuity: A trilogy for student success. GE Foundation. Retrieved from http://www.campbell-kibler.com/trilogy.pdf

Kahle, J., \& Meece, J. (1994). Research on gender issues in the classroom. In D. Gable (Ed.), Handbook of research on science teaching and learning (pp. 542-557). New York: Macmillan.

Kane, J. (2011). Young African American children constructing academic identities in an urban science classroom. Science Education, 96, 457-487.

Kemmis, S., \& McTaggart, R. (2000). Participatory action research. In N. K. Denzin \& Y. S. Lincoln (Eds.), Handbook of qualitative research (2nd ed., pp. 567-605). Thousand Oaks, CA: Sage.

Lee, O., \& Luykx, A. (2007). Science education and student diversity: Race/ethnicity, language, culture, and socioeconomic status. In S. K. Abell \& N. G. Lederman (Eds.), Handbook of research on science education (pp. 171-198). Mahwah: Erlbaum.

Lee, V., \& Burkam, D. (1996). Gender difference in middle grades science achievement: Subject domain, ability level, and course emphasis. Science Education, 8o, 613-650.

Madriz, E. (2000). Focus groups in feminist research. In N. Denzin \& Y. Lincoln (Eds.), Handbook of qualitative research (pp. 835-850). Thousand Oaks, CA: Sage.

Moje, E. B., Tehani, C., Carrillo, R., \& Marx, R. W. (2001). Maestro, what is "quality"? Language, literacy, and discourse in project-based science. Lournal of Research in Science Teaching, 38, 469-498.

National Research Council. (2012). A framework for K-12 science education: Practices, crosscutting concepts, and core ideas. Washington, DC: National Academies Press.

Packard, B., \& Wong, E. D. (1999). Future images and women's career decisions in science. Paper presented to the American Educational Research Association, Montreal.

Quigley, C., Beeman-Cadwallader, N., Riggs, M., Rodriquez, A., \& Buck, G. (2009). Deer tracks in the city? Problem-based learning in a kindergarten classroom. Science and Children, 47(2), 34-37.

Reinharz, S. (1992). Feminist methods in social research. New York: Oxford University Press.

Rollock, N. (2007). Why Black girls don't matter: Deconstructing gendered and racialised discourses of academic success in an inner city school. British Journal of Learning Support, 22 (4), 197-202.

Scantlebury, K., \& Baker, D. (2007). Gender issues in science education research: Remembering where the difference lies. In S. K. Abell \& N. G. Lederman (Eds.), Handbook of research on science education (pp. 257-286). Mahwah: NJ: Erlbaum.

Simpson, J., \& Parsons, E. (2008). African American perspectives and informal science educational experiences. Science Education, 93, 293-321.

Tal, T., Krajcik, J., \& Blumenfeld, P. C. (2006). Urban schools' teachers enacting project-based science. Lournal of Research and Science Teaching, 43, 722-745.

Tatum, B. (2003). Why are all the Black kids sitting together in the cafeteria? New York: Basic Books.

Varelas, M., Kane, J., \& Wylie, C. (2011). Young African American children's representation of self, science, and school: Making sense of difference. Science Education, 95(5), 824-851.

Varelas, M., Kane, J., \& Wylie, C. (2012). Young Black children and science: Chronotypes of narratives around their science journals. Iournal of Research in Science Teaching, 49(5), 568-596. 
Weinburgh, M. H. (2003). The effects of systemic reform on urban, African American fifth-grade students' attitudes toward science. Lournal of Women and Minorities in Science and Engineering, 9(1), 53-72.

Weinburgh, M. H., \& Steele, D. (2000). The modified attitudes toward science inventory: Developing an instrument to be used with fifth grade urban students. Journal of Women and Minorities in Science and Enoineering, 6(1), 87-94.

Wilkinson, S. (1999). How useful is focus group research? In R. Barbour \& J. Kitzinger (Eds.), Developing focus group research: Politics, theory and practice. (pp. 64-78). Thousand Oaks, CA: Sage.

Zohar, A. (2006). Connected knowledge in science and mathematics education. International Journal of Science Education, 28, 1579-1599. 